\title{
INFRAESTRUTURA RODOVIÁRIA E MOBILIDADE PENDULAR NAS MICRORREGIÕES DE MINAS GERAIS
}

\author{
Ralfo Matos* \\ Carlos Lobo ${ }^{* *}$ \\ André Simplício ${ }^{\text {**** }}$
}

\begin{abstract}
RESUMO
A mobilidade pendular tem sido utilizada como indicador de integração entre lugares. Tornou-se relevante, com a consolidação dos processos de industrialização e urbanização, examinar a mobilidade pendular em diversas áreas das ciências humanas e sociais. Porém, são ainda raras as iniciativas de contrapor os movimentos pendulares e a infraestrutura rodoviária que faculta o deslocamento dos indivíduos no espaço. Esse artigo procura aproximar essas duas dimensões ao analisar o caso de Minas Gerais, tendo como objetivo principal avaliar a possível influência da densidade rodoviária na intensidade dos deslocamentos diários para trabalho e estudo nas microrregiões de Minas Gerais. Como parte da metodologia de análise, foi proposto um Índice de Densidade Rodoviária, que considera as rodovias pavimentadas (simples e duplicadas) que compõem a malha do estado até o ano de 2013 (excluídas as ligações hidroviárias e ferroviárias), contrapostas ao número de sedes municipais e à população residente em cada microrregião. Para análise dos movimentos pendulares foram utilizados os microdados amostrais do Censo Demográfico de 2010, por meio da combinação das variáveis que identificam o município de trabalho e/ou estudo. Os resultados permitiram observar que, além de uma relação de baixa determinação direta, considerados os valores pouco significativos obtidos pela análise de regressão linear geral e local, as regiões do estado que possuíam densa malha rodoviária, em especial na região do triangulo mineiro, também exibiam baixo nível de mobilidade espacial da população. Há, ainda, as microrregiões que se destacavam pela alta mobilidade, como de Belo Horizonte, Ipatinga e Conselheiro Lafaiete,

\footnotetext{
* Doutor em Demografia. Professor Titular do Departamento e do Programa de Pós-Graduação em Geografia do IGC/UFMG. E-mail: ralfomatos@gmail.com.

** Doutor em Geografia. Professor Adjunto do Departamento do Departamento e do Programa de Pós-Graduação em Geografia e Análise e Modelagem de Sistemas Ambientais do IGC/UFMG. E-mail: carlosfflobo@gmail.com.br.

**** Mestre em Geografia. Doutorando em Geografia pela Universidade Federal de Minas Gerais.
} 
localizadas na porção central de Minas, apesar de uma infraestrutura rodoviária "deficitária". Contudo, nas regiões ao norte e sul do estado o baixo Índice de Densidade Rodoviária (IDR) coexiste com a Razão de Pendularidade (RP) pouco expressiva. Nesses casos, a baixa mobilidade decorre provavelmente da maior participação do setor econômico agrícola, que tradicionalmente exige menor necessidade de deslocamento diário da força de trabalho quando comparado às necessidades dos setores secundário e terciário, característicos dos principais centros urbanos.

\section{INTRODUÇÃO}

A mobilidade pendular é um fenômeno demográfico que se torna parte da realidade de um número crescente de pessoas que se deslocam diariamente de um município a outro para trabalhar ou estudar. Esse fenômeno, que tem atraído a atenção de um número crescente de estudiosos, guarda vínculos de conexão com a problemática urbana contemporânea, particularmente a referida aos fluxos diários intrametropolitanos, a partir dos quais se pode cartografar o grau e intensidade da articulação entre municípios conurbados geralmente populosos.

Diante dessas evidências pode-se concluir que áreas densamente ocupadas dotadas de inúmeras conexões rodoviárias e relativamente próximas geograficamente são mais propensas a disseminar efeitos de polarização e fluxos de pendularidade. Isso parece óbvio, mas será que essa assertiva é de fato verificável empiricamente?

Apesar de a relação entre o movimento pendular e os meios de transporte ser conhecida (BEAUJEU-GARNIER, 1980), e por vezes bem enfatizada (MOURA, 2005; BRANCO et al., 2005) pouca atenção tem sido dada ao fato de que os deslocamentos pendulares podem guardar uma relação direta com a existência de espaços dotados de uma maior ou menor densidade de infraestrutura. Talvez um olhar excessivamente metropolitano sobre esse fenômeno possa levar a falsa conclusão de que a conectividade dos lugares é um dado natural, fruto da conurbação. Com isso, a desigualdade em termos de mobilidade e acessibilidade não é explorada, tampouco suas consequências.

Contudo, o que aparentemente soa evidente pode resultar em equívocos, inclusive porque mesmo em áreas metropolitanas nem todos os municípios conurbados estão plenamente articulados, nem a mobilidade pendular se afigure relevante. Diante das lacunas 
existentes e de questões ainda não resolvidas no tocante aos nexos que unem mobilidade pendular e infraestrutura rodoviária procura-se nesse artigo comparar, mensurar, analisar e extrair conclusões sobre a relação entre oferta de infraestrutura de transporte e intensidade de fluxos pendulares nas 66 microrregiões do estado de Minas Gerais.

\section{SOBRE OS MOVIMENTOS PENDULARES E MOBILIDADE NO ESPAÇO}

O movimento pendular se refere ao movimento realizado por um conjunto de indivíduos que se desloca entre uma unidade espacial em que se localiza seu domicílio e outra onde trabalha ou estuda, conforme quesito dos Censos Demográficos brasileiro. Essas unidades espaciais frequentemente são municípios relativamente próximos e envolvem deslocamentos curtos (embora haja pendularidades que ultrapassam as 24 horas de um dia e refiram-se a deslocamentos entre áreas mais distantes).

Nos movimentos a curta distância o indivíduo pode gastar horas no deslocamento se os municípios de trabalho e residência, por exemplo, não contarem com vias e meios de transporte eficientes, ou se houver trechos muito congestionados em uma grande metrópole com dezenas de municípios conurbados, muitos dos quais a oferecer postos de trabalho para residentes das mais diversas procedências na metrópole.

A despeito de a mobilidade pendular diferir dos movimentos migratórios, ela traz alguns efeitos similares uma vez que efetivamente a unidade espacial de referência experimenta um acréscimo populacional mais ou menos significativo em determinados momentos ao longo do dia. De acordo com Aranha (2005),

Do ponto de vista demográfico, os deslocamentos pendulares modificam provisoriamente o volume populacional do município e aumentam ou diminuem seu tamanho dependendo das características de cada área. Assim, se o município for mais concentrador ou mais dispersor, os deslocamentos podem gerar maior ou menor demanda por serviços ou bens ou aumentar sua oferta para a população residente. (ARANHA, 2005, p. 96)

Algumas cidades se "beneficiam" do aumento provisório da população por causa do incremento da demanda de vários serviços locais. Do lado da origem, entretanto, pode ocorrer uma circunstância urbana que resulta nas chamadas "cidades-dormitórios". Esse tipo de 
cidade foi objeto da preocupação de planejadores urbanos em face da condição "pouco animada" do ponto de vista urbanístico desses municípios, vários deles com infraestrutura urbana precária, parcelamentos irregulares (e presença de lotes relativamente baratos) e muitos trabalhadores pouco qualificados. A paisagem dominada por moradias inacabadas, produto da autoconstrução ou mutirão é algo bastante conhecido nas periferias das metrópoles brasileiras. As administrações locais dificilmente aceitam de bom grado o rótulo de "cidade dormitório" e seus significados discriminatórios e buscam tenazmente alterar essa realidade.

A mobilidade pendular pode, no entanto, se referir a outro tipo de configuração urbana: a que diz respeito a municípios com muitas famílias de alta renda residindo em condomínios fechados que se deslocam diariamente para outros municípios para trabalhar ou estudar. Essa situação pode ser o resultado de movimentos migratórios no interior de regiões metropolitanas envolvendo camadas de média e alta renda em busca maior qualidade ambiental, menos violência existentes em municípios mais distantes do local de trabalho. Essas populações realizam a chamada mobilidade residencial.

A mobilidade residencial refere-se aos deslocamentos da população no interior de uma determinada unidade administrativa tendo como unidade mínima de referência o município, pelo fato que a mudança de residência não implica, necessariamente, mudança de emprego ou atividade. (JARDIM e ERVATTI, 2006)

Pode-se assim cogitar que a mobilidade pendular seja consequência da migração intrametropolitana determinada pela expansão dos vetores de expansão urbana dentro e/ou fora da metrópole. Isso reflete escolhas residenciais de segmentos da população de alta renda na expectativa de que externalidades positivas compensam os custos adicionais da distância ao trabalho, ou, no caso dos trabalhadores de baixa renda, a ação excludente do mercado imobiliário e/ou do mercado de trabalho (BRITO e SOUZA, 2005).

Segundo Beaujeu-Garnier (1980) o movimento pendular pode também se dar em função da falta de sincronia entre o desenvolvimento urbano e econômico, uma vez que o tecido urbano não é planejado para comportar adequadamente as funções econômicas articuladas à habitação. Para essa mesma autora a "multiplicação das facilidades de transporte é a base fundamental" para a expansão dos movimentos pendulares. Essa assertiva sugere que a facilidade nos transportes, ou a maior oferta de infraestrutura para o transporte seja um fator 
relevante que interfere nos movimentos pendulares. O acesso de indivíduos a meios de transporte mais eficazes parece ser essencial para a expansão da mobilidade intraurbana. Para Jones (1981, p.1) mobilidade

é a habilidade de um indivíduo, ou tipo de pessoa, de se deslocar. O que envolve dois componentes. O primeiro deles depende da performance do sistema de transportes, que é afetado pela localidade da pessoa, a hora do dia e a direção onde ela deseja viajar. O segundo componente depende das características do indivíduo como quando o carro está disponível, pode pagar um táxi, ônibus, tarifas rodoviárias ou aeroviárias, se é capaz de andar ou usar o transporte público, ou se tem conhecimento das opções disponíveis para ele. Em outras palavras, o primeiro elemento diz respeito a efetividade do sistema de transporte conectar locais espacialmente separados e o segundo elemento diz respeito do acesso de cada indivíduo aos sistemas de transporte.

A infraestrutura existente se afigura então como um pré-requisito decisivo para o deslocamento dos indivíduos. É razoável intuir que uma boa infraestrutura viária favoreça a multiplicação de movimentos entre localidades mais distantes em intervalos de tempo relativamente menor.

É evidente que a existência de linhas ferroviárias expressas, de serviços suburbanos com poucas paradas, e de rodovias, permite que localidades muito distantes tenham melhores ligações com as metrópoles que lugares mais próximos que, no entanto, dispõe apenas de serviço inferior ou lento. (BEAUJEU-GARNIER, p. 295).

Se a infraestrutura e os transportes são tão básicos para o deslocamento dos indivíduos conviria buscar associações mais diretas entre disponibilidade de meios de circulação e mobilidade da população. Dados sobre essa temática são pouco explorados nas Ciências Sociais, a despeito de referências textuais sobre a importância das redes de transporte e circulação em estudos sobre a geografia da circulação (SILVEIRA et al. 2011, PEREIRA e LESSA, 2009, SANTOS e SILVEIRA (2001). 
Nas chamadas Ciências Sociais Aplicadas, os estudos sobre essa questão geralmente surge no interior dos diagnósticos e planos urbanísticos ou em investigações que se concentram nas consequências do uso excessivo do automóvel e precariedade do transporte coletivo (MOURA, 2005; BRANCO et al., 2005, MARICATO, 2008). São poucas as abordagens que associam "taxas de motorização" com mobilidade pendular, por exemplo. Assim, no debate sobre movimento das pessoas em grandes áreas urbanizadas pouca atenção é dada à forma como elas se deslocam. Isso talvez se deva ao fato de que dentro da tradição do estudo das migrações tais associações não sejam tão pertinentes quanto no caso de estudos sobre mobilidade pendular.

\section{O CAMINHO PROPOSTO}

Para tentar contribuir com a lacuna existente na bibliografia pretende-se investigar de forma ainda preliminar dois tipos de dados e correlaciona-los. O primeiro, diz respeito aos fluxos de pendularidade mapeados segundo dados do Censo Demográfico de 2010 (deslocamentos realizados diariamente para trabalho ou estudo). O quociente entre a população que realiza o movimento pendular em uma dada microrregião será $M P_{\mathrm{i}}$ e a população total da microrregião $P_{\mathrm{i}}$ nos retornou a Razão de Pendularidade (RP), o que nos permite entender a intensidade desse movimento dentro do conjunto da população.

$$
\mathrm{RP}=\frac{\sum_{j}^{n} M P i}{\sum_{j}^{n} P i}
$$

O segundo dado é o da oferta de infraestrutura de transportes para movimentos intermunicipais. Como a área de estudo se limita ao estado de Minas Gerais, essa informação se traduz na oferta de infraestrutura rodoviária, uma vez que não o transporte ferroviário ou hidroviário não constitui uma alternativa de transporte de massa na maior parte do Estado. Para tanto construiu-se uma base georreferenciada de rodovias tendo por base o Mapa Rodoviário 2013 (DER-MG, 2014).

De fato, ainda há em Minas Gerais muitas conexões entre distritos e até entre municípios realizadas por estradas de terra. Contudo considerou-se mais pertinente considerar apenas as vias pavimentadas, mais adequadas a deslocamentos rápidos, ainda que 
estratificadas em dois tipos: as pavimentadas que possuem uma única faixa de rodagem em cada sentido (peso 1); e as duplicadas, com duas faixas de rodagem em cada sentido (peso 2), como representado na Figura 1. O Índice de Densidade Rodoviária (IDR) foi obtido pela razão entre o somatório da extensão ponderada da Malha Rodoviária $\left(M R_{\mathrm{i}}\right)$ e produto entre o logaritmo da população residente $\left(\log \left(P_{\mathrm{i}}\right)\right.$ e o número de municípios $\left(N_{\mathrm{i}}\right)$ em cada mesorregião em 2010.

$$
\mathrm{IDR}=\frac{\sum_{j}^{n} M R i}{\operatorname{lOG}\left(\sum_{j}^{n} P i\right) * \sum_{j}^{n} N i}
$$

Recorreu-se, ainda, ao modelo de regressão linear para avaliar o nível de predição da mobilidade pendular (variável dependente) na densidade rodoviária (variável explicativa), incluindo a utilização do modelo de regressão local denominado "Geographically Weighted Regression" (GWR). Trata-se de uma ferramenta desenvolvida com o propósito de analisar fenômenos que sofrem variação na área estudada, derivada da heterogeneidade espacial. O modelo GWR tem como base o ajustamento de um modelo de regressão local para cada ponto no conjunto de dados, ponderando as observações em razão da distância a este ponto. $\mathrm{O}$ pressuposto é que pontos mais próximos do ponto de estudo tenham maiores influencias nos parâmetros da regressão do que aqueles obtidos mais distantes (CARVALHO et al., 2006). Foi utilizado o método para definir a largura de banda ou vizinhos foi AICc (Akaike Information Criterion). Trata-se de uma medida de desempenho e é útil para comparar diferentes modelos de regressão. Leva em conta a complexidade do modelo e fornece um melhor ajuste aos dados observados. AICC não é uma medida absoluta de bondade de ajuste, mas é útil para comparar modelos com diferentes variáveis explicativas, enquanto eles se aplicam à mesma variável dependente. 


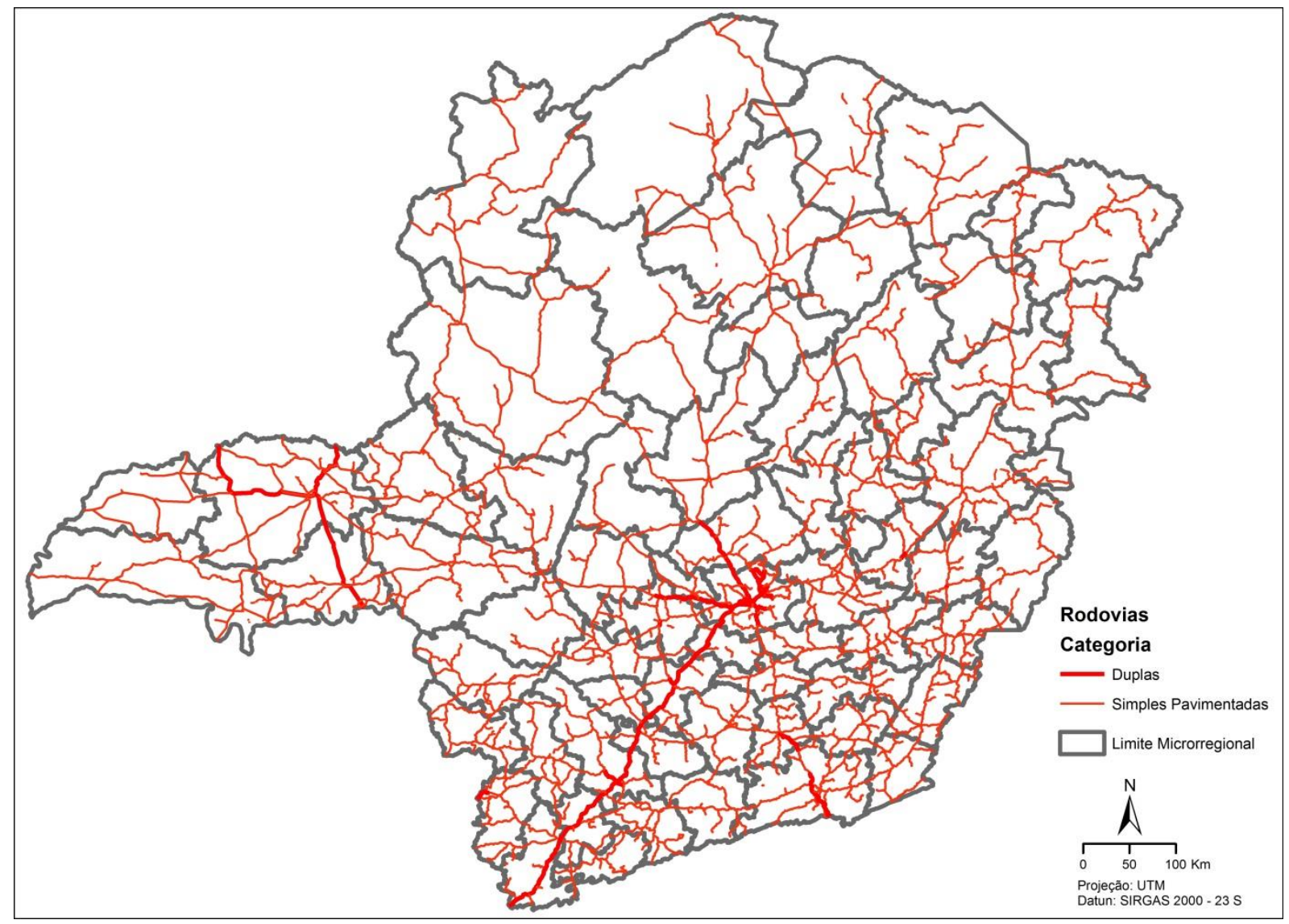

Figura 1: Malha Rodoviária das Mesorregiões de Minas Gerais - 2010

Fonte: DNIT/DER

\section{RESULTADOS E DISCUSSÕES}

A Figura 2, que representa de modo sintético a distribuição espacial da mobilidade da população, com base na denominada Razão de Pendularidade, permite observar que as microrregiões que mostram maior intensidade nos movimentos pendulares correspondem àqueles mais industrializadas, a exemplo de Belo Horizonte, Ipatinga e Conselheiro Lafaiete, geralmente vizinhas de outras com RP também elevados. As situações de média a baixa intensidade aparecem em 52 das 66 microrregiões.

Com base na analise da Figura 3, que apresenta a espacialização do IDR, pode-se notar que as regiões de Média a Baixa densidade referem-se a 56 das 66 microrregiões. A microrregião de Belo Horizonte e seu entorno apresenta uma densidade considerável, mas devido a sua grande população a infraestrutura viária se apresenta insuficiente, especialmente 
se comparada com a de regiões como Triângulo e Noroeste de Minas Gerais. Essas duas grandes regiões aglutinam todas as microrregiões de alta densidade, mostrando que a oferta de rodovias é superior do ponto de vista demográfico.

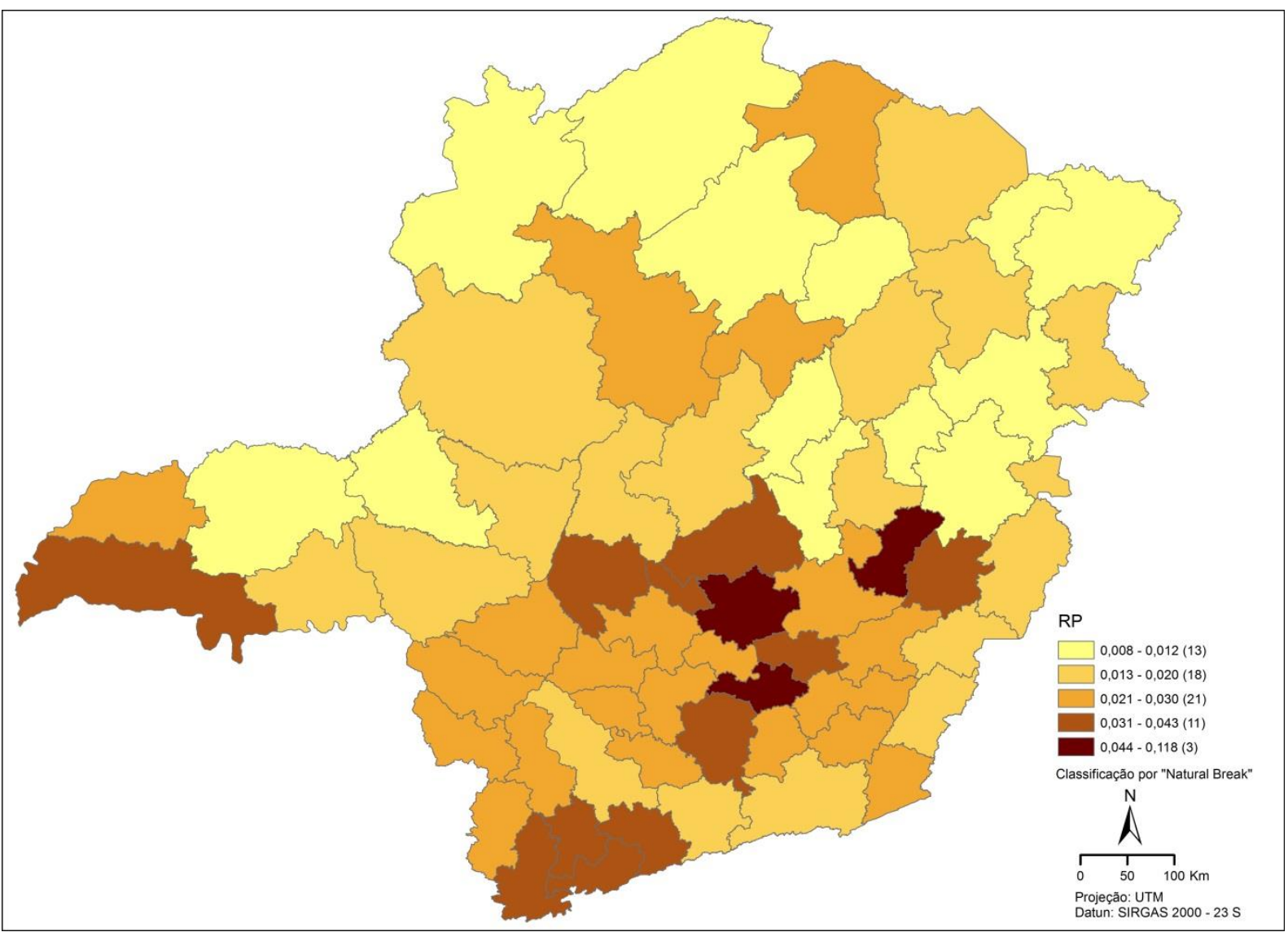

Figura 2: Razão de Pendularidade (RP) das Mesorregiões de Minas Gerais - 2010

Fonte: Censo Demográfico 2010 (dados da amostra) 


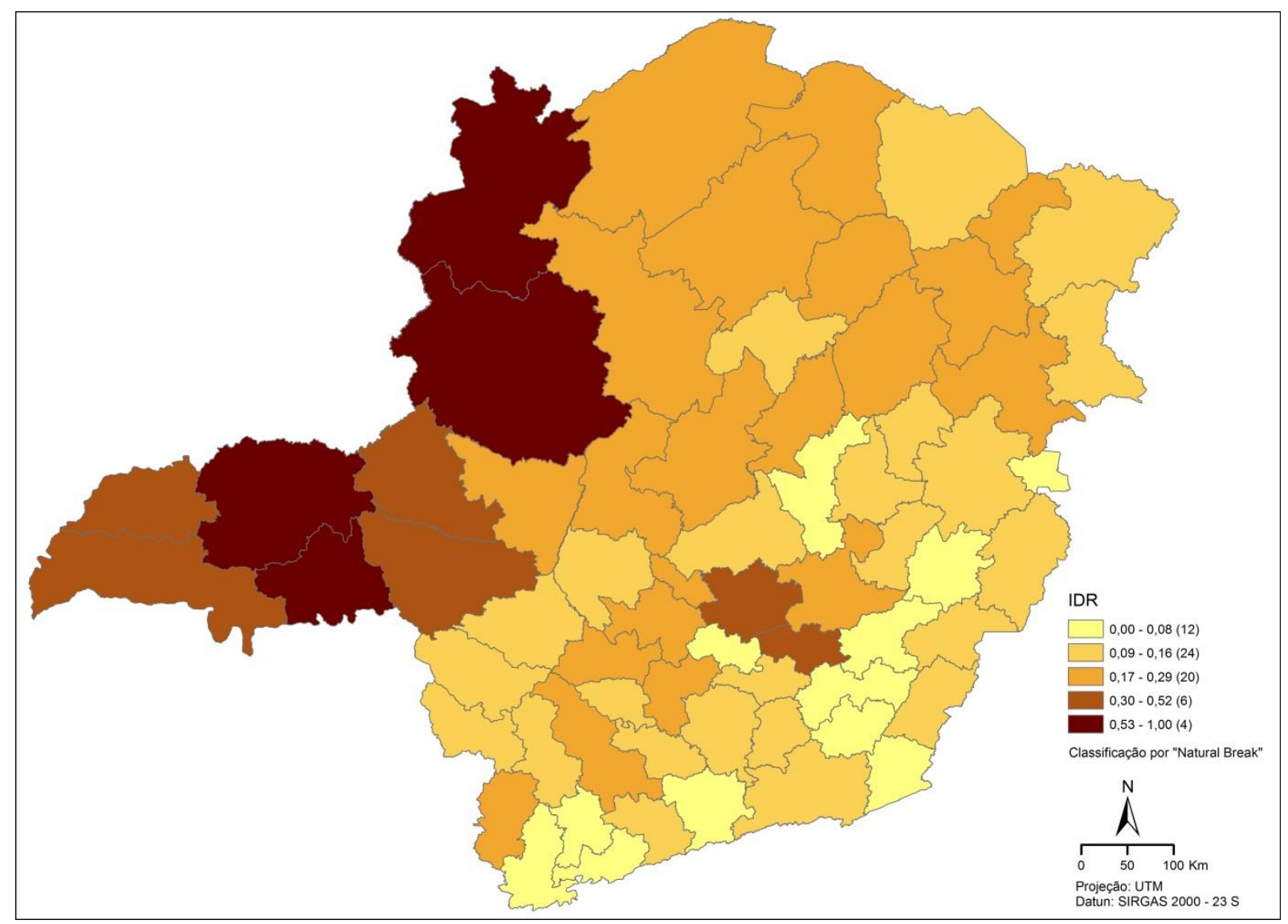

Figura 3: Índice de densidade Rodoviária (IDR) das Mesorregiões de Minas Gerias - 2010 Fonte: Censo Demográfico 2010 e DNIT/DER

Há, ainda, as microrregiões que se destacavam pela alta mobilidade, como de Belo Horizonte, Ipatinga e Conselheiro Lafaiete, localizadas na porção central de Minas, apesar de uma infraestrutura rodoviária "deficitária". Contudo, nas regiões ao norte e sul do estado o baixo Índice de Densidade Rodoviária (IDR) coexiste com a Razão de Pendularidade (RP) pouco expressiva. Nesses casos, a baixa mobilidade decorre provavelmente da maior participação do setor econômico agrícola, que tradicionalmente exige menor necessidade de deslocamento diário da força de trabalho quando comparado às necessidades dos setores secundário e terciário, característicos dos principais centros urbanos ao passo que demanda robusta infraestrutura para deslocamento insumos e produtos.

Em geral, como representado nas Figuras 4 e 5, tanto o valor de $\mathrm{R}_{2}$ Geral quanto os escores regionais não indicam predição significativa da Razão de Pendularidade com base no Índice de Densidade Rodoviária, cujos ajustes maiores ao modelo correspondem as microrregiões do Triângulo Mineiro. Os valores de pendularida estão consideravelmente mais 
elevados que aqueles preditos para o modelo em algumas microrregiões da porção central do estado, notadamente na de Belo Horizonte, Ipatinga e Conselheiro Lafaiete. Em boa parte das demais microrregiões o valor de pendularidade está aquém dos parâmetros de projeção.

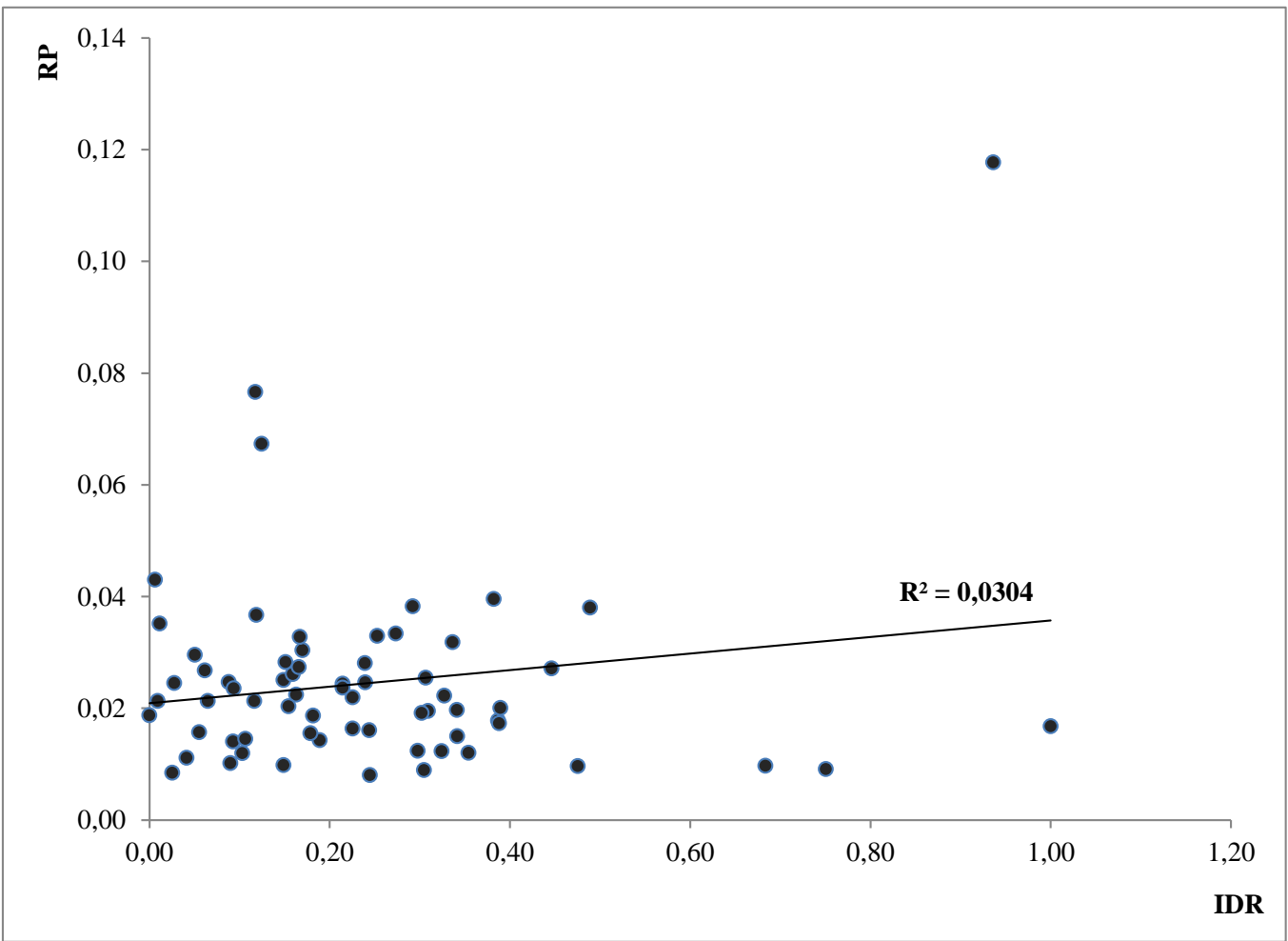

Figura 4: Dispersão XY e regressão linear - IDR (variável explicativa) e RP (variável dependente) - Mesorregiões de Minas Gerais, 2010

Fonte: Censo Demográfico 2010 (dados da amostra) e DNIT/DER 


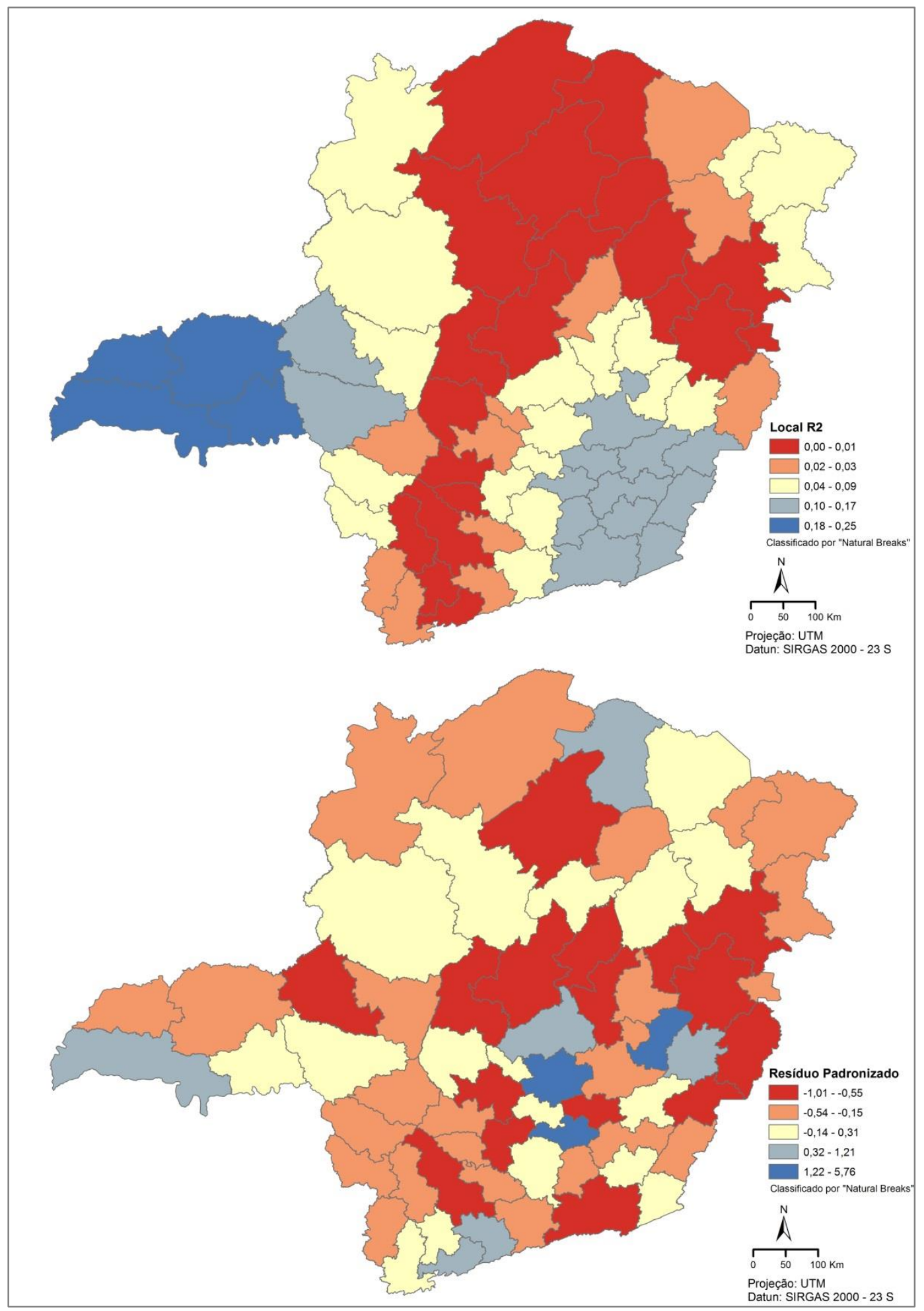

Figura 5: Regressão Geograficamente Ponderada (GWR) DR (variável explicativa) e RP (variável dependente) - Mesorregiões de Minas Gerais, 2010 Fonte: Censo Demográfico 2010 (dados da amostra) e DNIT/DER 


\section{CONCLUSÕES}

Considerando as restrições naturais ao recorte microrregional analisado e a escala temporal circunscrita a um momento específico, pode-se concluir que não há uma relação direta entre os indicadores analisados. A pendularidade não é diretamente proporcional à oferta de infraestrutura, dada pela malha rodoviária considerado. Esse fato sugere que, além do relativo descompasso entre a oferta de infraestrutura rodoviária e demanda para a migração pendular, há provavelmente a influência de outros fatores que podem induzir a intensidade e direção movimento populacional.

Outra observação refere-se a elevada mobilidade pendular ser intensa na RMBH, em contraposição a baixa mobilidade em boa parte das demais regiões do interior do estado também . Contudo, quando analisados os indicadores de Densidade Rodoviária, os escores da região central do estado são menos expressivos. Nesse indicador, a situação mais favorável refere-se às microrregiões do Triângulo mineiro.

Por fim, vale ressaltar a necessidade de se estudar mais afundo tanto a migração como a mobilidade pendular, incorporando outras variáveis, bem como propondo novos parâmetros da análise da infraestrutura, além da malha rodoviária. Ainda que os resultados aqui apresentados sejam limitados, os indicadores propostos servem como ponto de reflexão sobre a eficiência e eficácia na ação do poder público na oferta de meios que estimulem e não impeçam a mobilidade espacial da população, fundamental ao dinamismo regional.

\section{REFERÊNCIAS}

ARANHA, Valmir. Mobilidade pendular na metrópole paulista. São Paulo Em Perspectiva, v. 19, n. 4, p. 96-109, out./dez. 2005.

BEAUJEU-GARNIER, J. Geografia da população. São Paulo: Companhia Editora Nacional, 1980.

BRANCO, Maria Luiza Castello; FIRKOWSKI, Olga L. C. F.; MOURA, Rosa. Mobilidade pendular: abordagem teórica e reflexões sobre o uso do indicador. Anais do XI Encontro Nacional da Associação Nacional de Pesquisa e Pós-Graduação em Planejamento Urbano e Regional. Salvador, 2005. 
DER-MG. Derpartamento de Estradas de Rodagem de Minas Gerais. Mapa rodoviário de Minas Gerais 2013. Curitiba: Temática Cartografia, 2014.

JARDIM; EVERATTI. Migração pendular intrametropolitana no Rio De Janeiro: A condição de renda das pessoas que trabalham ou estudam fora do município de residência em 1980 e 2000. Anais do XV Encontro Nacional de Estudos Populacionais, ABEP. Caxambu. 2006.

JONES, S.R. Accessibility measures: a literature review. Transport and Road Research Laboratory, Laboratory Report 967, 1981.

MARICATO, Ermínia. A cidade e o automóvel. Ciência \& Ambiente, v.37, p.5-12, 2008.

MOURA, Rosa; BRANCO, Maria Luiza Castello; FIRKOWSKI, Olga L. C. F. Movimento pendular e perspectivas de pesquisas em aglomerados urbanos. São Paulo Em Perspectiva, v. 19, n. 4, p. 121-133, out./dez. 2005.

OJIMA, Robson; SILVA, Ricardo; PEREIRA, Rafael. A Mobilidade Pendular na Definição das Cidades-Dormitório: caracterização sociodemográfica e novas territorialidades no contexto da urbanização brasileira. Anais do XVI Encontro Nacional de Estudos Populacionais, ABEP. Campinas. 2008.

PEREIRA, W.A.A. et al. Aspectos da crise do transporte urbano. Revista dos Transportes Públicos - ANTP, São Paulo, ano 23, n. 89, 2000.

PEREIRA, Mirlei Fechini Vicente. Redes, sistemas de transportes e as novas dinâmicas do território no período atual: notas sobre o caso brasileiro. Revista Sociedade \& Natureza. n. 1 vol. 21, 2009.

PEREIRA, L. A. G.; LESSA, S. O processo de planejamento e desenvolvimento do transporte rodoviário no Brasil. Revista Sociedade \& Natureza v. 12, n. 40, p. 26 - 46 dez. 2011

SILVEIRA, Márcio Rogério (org.). Circulação, transportes e logística. São Paulo: Outras Expressões, 2011. (Coleção Geografia em Movimento)

SANTOS, M.; SILVEIRA, M. L. Brasil: território e sociedade no início do século XXI. 5a. ed. Rio de Janeiro: Record, 2001. 473p. 